Aim of the study: Many studies have shown that interferon- $\alpha$ (IFN- $\alpha$ ) enhances the antiproliferative effect of gefitinib in some solid tumours. We aimed to determine the effect of combining IFN- $\alpha$ with gefitinib in human non-small cell lung cancer (NSCLC) cell lines (A549, H1299, HCC827) with different EGFR and $K$-Ras gene statuses. Material and methods: An MTT assay was used to assess cell proliferation. Apoptosis was detected by an Annexin V/propidium iodide assay using flow cytometry, and western blotting was used to determine the expression of epidermal growth factor receptor/ phosphorylated epidermal growth factor receptor (EGFR/p-EGFR) and signal transducers and activators of transcription 3/phosphorylated signal transducers and activators of transcription 3 (STAT3/p-STAT3).

Results: There was an additive interaction when gefitinib was combined with IFN- $\alpha$ in all cell lines; however there was antagonism when gefitinib followed IFN- $\alpha$ pretreatment in three cell lines. Notably, IFN- $\alpha$ pretreatment significantly reduced the gefitinib sensitivity of HCC827 cells. Surprisingly, while IFN- $\alpha$ inhibited STAT3 phosphorylation in cell lines, gefitinib could do so.

Conclusions: The results might confirm the hypothesis that IFN- $\alpha$ induces gefitinib sensitivity of NSCLC, and IFN- $\alpha$ inhibits phosphorylation of STAT3, which may be dependent on EGFR signal activation playing a role in the reduction of gefitinib sensitivity after IFN- $\alpha$ treatment in NSCLC cell lines.

Key words: interferon- $\alpha$, gefitinib, antagonism, non-small cell lung cancer, STAT3.

Contemp Oncol (Pozn) 2016; 20 (4): 320-326 DOI: $10.5114 /$ wo. 2016.61853

\section{Interferon- $\alpha$ reduces the gefitinib sensitivity of human non-small cell lung cancer}

\author{
Chi Pan ${ }^{1}$, Shanshan Weng ${ }^{2}$, Yin Duan ${ }^{3}$, Ling Ding ${ }^{2}$, Suzhan Zhang ${ }^{3}$, \\ Jianjin Huang ${ }^{2}$
}

\author{
${ }^{1}$ Cancer Institute, School of Medicine, Zhejiang University, HangZhou, PR China \\ ${ }^{2}$ Medical Oncology, The Second Affiliated Hospital, School of Medicine, Zhejiang \\ University, HangZhou, PR China \\ ${ }^{3}$ Cancer Institute, The Second Affiliated Hospital, School of Medicine, Zhejiang \\ University, HangZhou, PR China
}

Gefitinib, an epidermal growth factor receptor-tyrosine kinase inhibitor (EGFR-TKI), has been widely applied in non-small cell lung cancer (NSCLC) therapy [1]. However, the emergence of drug resistance is a major obstacle to the further application of gefitinib.

There are numerous reports on preclinical studies of interferon (IFN) and its positive synergistic effect when combined with anti-EGFR agents in various tumours, such as renal cell carcinoma [2], hepatocellular carcinoma [3], and bladder carcinoma [4]. In addition, many studies have verified the positive combined effect of IFN and EGFR-TKI in human colon cancer cells $[5,6]$ and head and neck cancer cells [7]; it is hypothesised that IFN can activate EGFR signalling by upregulating EGFR [8]. As EGFR-TKI has been applied primarily in advanced NSCLC, our experiment was designed to explore the combinational or sequential role of IFN- $\alpha$ and gefitinib in NSCLC cells possessing different genotypes, and to determine whether the synergistic effect of this combination therapy can occur in NSCLC. Disappointingly, it was observed that IFN- $\alpha$ reduced gefitinib sensitivity, particularly in NSCLC cells with EGFR-TKI-sensitive mutations.

\section{Materials and methods}

\section{Chemicals}

Interferon- $\alpha$ (Alfaron, recombinant IFN- $\alpha 2$ b; Hualida Biotechnology Co., Tianjin, China) had a specific activity of $3 \times 10^{6}$ units $/ \mathrm{ml}$ and $>99 \%$ purity. The selective EGFR-TKI gefitinib (GD760, Iressa), kindly provided by AstraZeneca (Macclesfield, Cheshire, UK), was dissolved in DMSO to a working concentration of $20 \mathrm{mM}$. Both drugs were stored at $-20^{\circ} \mathrm{C}$ in tightly sealed sterile tubes and diluted to the desired concentration in culture medium (RPMI 1640; Gibco, Grand Island, NY, USA) before being added to the cells.

\section{Cell lines}

Four human NSCLC cell lines were used: A549, H1299, and HCC827 (Cell Bank of Chinese Academy of Sciences, Shanghai, China), which have different EGFR and K-Ras gene statuses (exons 18-21 of the EGFR gene and exons $2-3$ of the $K$-Ras gene were sequenced, A549 cell line harbours mutation (G12S) of K-Ras, HCC827 cell line carries EGFR 19Del, and the EGFR and K-Ras of H1299 cell line are all wild type, data not shown). The cell lines were grown in RPMI 1640 (Gibco) supplemented with 10\% foetal bovine serum and maintained at $37^{\circ} \mathrm{C}$ in a humidified atmosphere containing $5 \% \mathrm{CO}_{2}$ and $95 \%$ air. 


\section{Treatment regimens}

Four different experimental regimens were investigated to evaluate the impact of IFN- $\alpha$ pretreatment on the antiproliferative effect of gefitinib:

- I, 72-hour incubation with gefitinib or IFN- $\alpha$ alone;

- II, 72-hour incubation with gefitinib (at the indicated concentrations in Figure 2) $+10^{4} \mathrm{IU} / \mathrm{ml}$ IFN- $\alpha$ (at the concentration of $10^{4} \mathrm{IU} / \mathrm{ml}$, IFN- $\alpha$ inhibits the proliferation of these lung cancer cells obviously);

- III, 72-hour pretreatment with $10^{4} \mathrm{IU} / \mathrm{ml} \mathrm{IFN}-\alpha$, following which the IFN- $\alpha$ was removed by washing twice with phosphate-buffered saline (PBS), followed by 72-hour incubation with gefitinib $+10^{4} \mathrm{IU} / \mathrm{ml} \mathrm{IFN}-\alpha$;

- IV, 72-hour pretreatment with $10^{4} \mathrm{IU} / \mathrm{ml} \mathrm{IFN}-\alpha$, following which the IFN- $\alpha$ was removed by washing twice with PBS, followed by 72-hour incubation with gefitinib.

Control cells were processed in the same manner but with drug-free medium (placebo) instead of gefitinib.

\section{Cell proliferation assay}

The 3-(4,5-dimethylthiazol-2-yl)-2,5-diphenyltetrazolium bromide (MTT)-tetrazolium dye assay was used to evaluate cell viability. $100 \mu \mathrm{l}$ exponential growth-phase cells (about 3500 cells in total) were seeded into 96-well plastic plates, incubated overnight, and added $100 \mu \mathrm{l}$ serial dilutions of gefitinib, IFN- $\alpha$, or gefitinib + IFN- $\alpha$ into each well. After 72-hour incubation at $37^{\circ} \mathrm{C}, 20 \mu 15 \mathrm{mg} / \mathrm{ml} \mathrm{MTT}$ solution was added into each well and the cells were incubated for four hours. The media were removed and $150 \mu$ I DMSO was added into each well to dissolve the MTT completely, and the absorbance values were read at $570 \mathrm{~nm}$ using a microplate reader (Model 680; Bio-Rad, Hercules, CA, USA). At least three replicate wells were used for each drug concentration, and the experiment was carried out independently at least three times. Cell proliferation is expressed as the percentage of drug-treated surviving cells versus control cells (in which viability was considered $100 \%$ ).

\section{Flow cytometry}

Apoptosis was detected using Annexin V/propidium iodide (PI) double staining. Cells were incubated for 72 hours in drug-free medium (control), $10^{4} \mathrm{IU} / \mathrm{ml} \mathrm{IFN-} \alpha$, gefitinib alone, or gefitinib after $10^{4} \mathrm{JU} / \mathrm{ml} \mathrm{IFN}-\alpha$ pretreatment. According to the IC50 of gefitinib in these three cell lines, the concentration of gefitinib for $\mathrm{Hcc} 827$ cell was $20 \mathrm{nM}$, and for other two cell lines it was $10 \mu \mathrm{M}$. The cells were harvested by trypsinisation, washed twice with PBS, incubated in 500 $\mu \mathrm{l}$ binding buffer and $10 \mu \mathrm{l}$ Annexin V-FITC at room temperature for 30 minutes, and then $5 \mu \mathrm{PI}$ was added and incubated for five minutes. The cells were analysed using flow cytometry (BD FACSCanto II, BD Biosciences, San Jose, CA, USA), and the data were analysed with CellQuest software (Becton Dickinson, Franklin Lakes, NJ, USA). The experiments were performed independently three times.

\section{Western blot}

H1299 and HCC827 cells were treated with IFN- $\alpha\left(10^{4}\right.$ $\mathrm{IU} / \mathrm{ml}$ ) or gefitinib $(20 \mathrm{nM})$ alone or in combination for 48 hours, washed with cooled PBS three times, and then lysed in 50-100 $\mu \mathrm{l}$ mammalian protein extraction reagent containing a protease inhibitor cocktail for 30 minutes. The lysates were centrifuged at $12,000 \mathrm{~g}$ at $4^{\circ} \mathrm{C}$ for 10 minutes. The lysates were normalised for total protein content using a bicinchoninic acid assay, and $60 \mu \mathrm{g}$ protein samples were loaded on SDS-PAGE gels and transferred to PVDF membranes. The membranes were probed with rabbit monoclonal antibodies against phosphorylated (p)-EGFR, EGFR, p-STAT3 (signal transducers and activators of transcription 3), STAT3, and $\beta$-actin (Santa Cruz, Dallas, TX, USA) at $4^{\circ} \mathrm{C}$ overnight. After washing three times in TBS-T (Tris hydrochloride buffer containing 0.1\% Tween-20), the membranes were incubated with the goat polyclonal secondary antibody to rabbit for two hours at room temperature. The membranes were washed with TBS-T three times for 10 minutes and exposed to $\mathrm{X}$-ray film for $5-10$ minutes. The relative expression of protein was determined from the optical density ratio of the corresponding protein bands using BandScan 5.0 software (Glyko Inc., Upper Heyford, UK).

\section{Data analysis}

The combination indexes (Cls) were calculated as previously described [9] with minor modifications: $\mathrm{Cls}=\% \mathrm{AB} /$ $(\% \mathrm{~A} \times \% \mathrm{~B})$, where $\% \mathrm{~A}$ and $\% \mathrm{~B}$ are the effect of the individual drug and \%AB is the effect of the combination. $\mathrm{Cls}<1,=1$, and $>1$ indicates synergism, additive effect, and antagonism, respectively.

\section{Statistical analysis}

All data are expressed as the mean \pm standard error (SE) of at least three experiments. A two-tailed, independent Student's t-test was used to determine the differences between the pretreatment and control groups. $F$ test was used for assessment of distribution for analysed parameters. Differences at $p<0.05$ for the Student t-test were considered statistically significant. The statistical analysis was performed using IBM SPSS software (ver. 19, SPSS Inc., Chicago, IL, USA). Graphs were generated using GraphPad Prism software (ver. 5, GraphPad Software Inc., La Jolla, CA, USA).

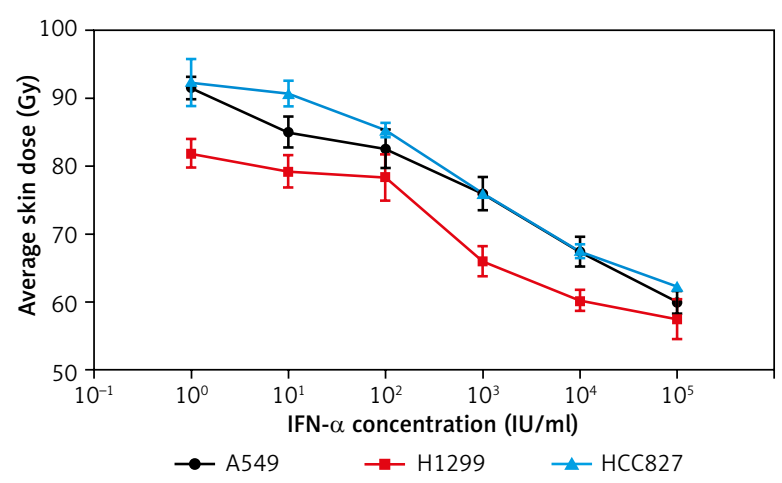

Fig. 1. Evaluation of the antiproliferative effect of IFN- $\alpha$ in NSCLC cell lines. Cell growth is expressed as the percentage of control for each concentration point. Points, mean of quadruplicates; bars, SE. $*, p<0.05$ 


\section{Results}

Evaluation of the antiproliferative effect of gefitinib and IFN- $\alpha$ in NSCLC cell lines

First, the effects of gefitinib or IFN- $\alpha$ on the growth of the A549, H1299, and HCC827 cells were evaluated. Dose-dependent growth inhibition was observed in all cell lines following 72-hour incubation with IFN- $\alpha$ (Fig. 1) or gefitinib (Fig. 2) alone. Moreover, the sensitivity to the antiproliferative effect of IFN- $\alpha$ did not appear to be associated with the EGFR and K-Ras gene statuses. It is known that gefitinib sensitivity is associated with EGFR mutation status [10-13]. Cell survival of the HCC827 cell line, containing

A
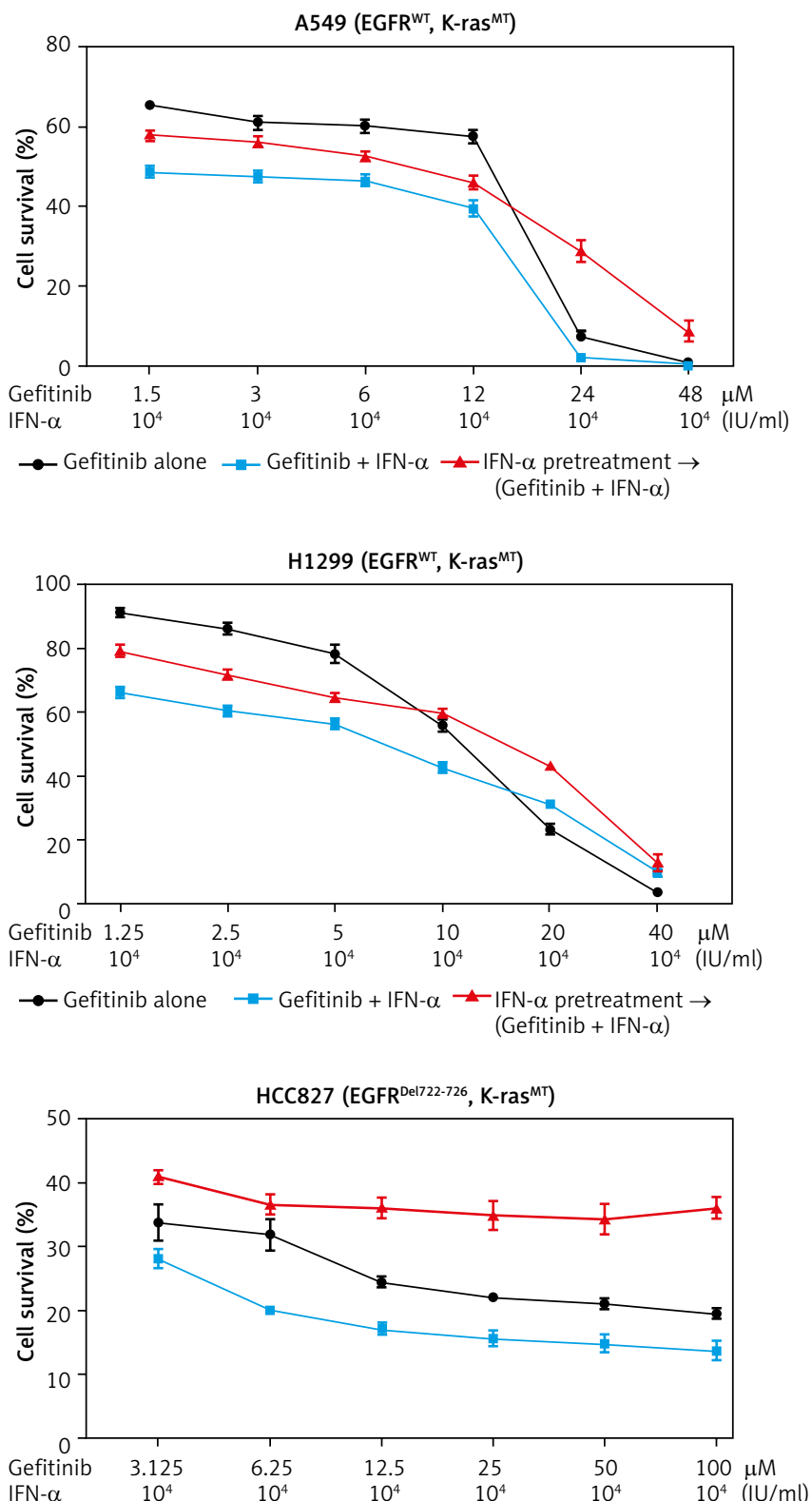

$\rightarrow$ Gefitinib alone $\rightarrow$ Gefitinib + IFN- $\alpha \rightarrow$ IFN- $\alpha$ pretreatment $\rightarrow$ $($ Gefitinib + IFN- $\alpha)$ the exon 19 deletion, was inhibited by up to $70 \%$ by 3.125 nM gefitinib, a concentration that was cytotoxic (Fig. 2), while the other two cell lines were all resistant to gefitinib.

Next, the antiproliferative effect of IFN- $\alpha$ alone in the cell lines was evaluated. Cell survivals were similar among three cell lines (A549: 71.8\%, H1299: 67.9\%, and HCC827: $63.2 \%)$.

\section{Additive/antagonistic antiproliferative effect of IFN- $\alpha$ /gefitinib combination}

We investigated whether a synergistic effect on NSCLC cells could be obtained by combining gefitinib with IFN- $\alpha$. However, it was found that when gefitinib was adminis-

B
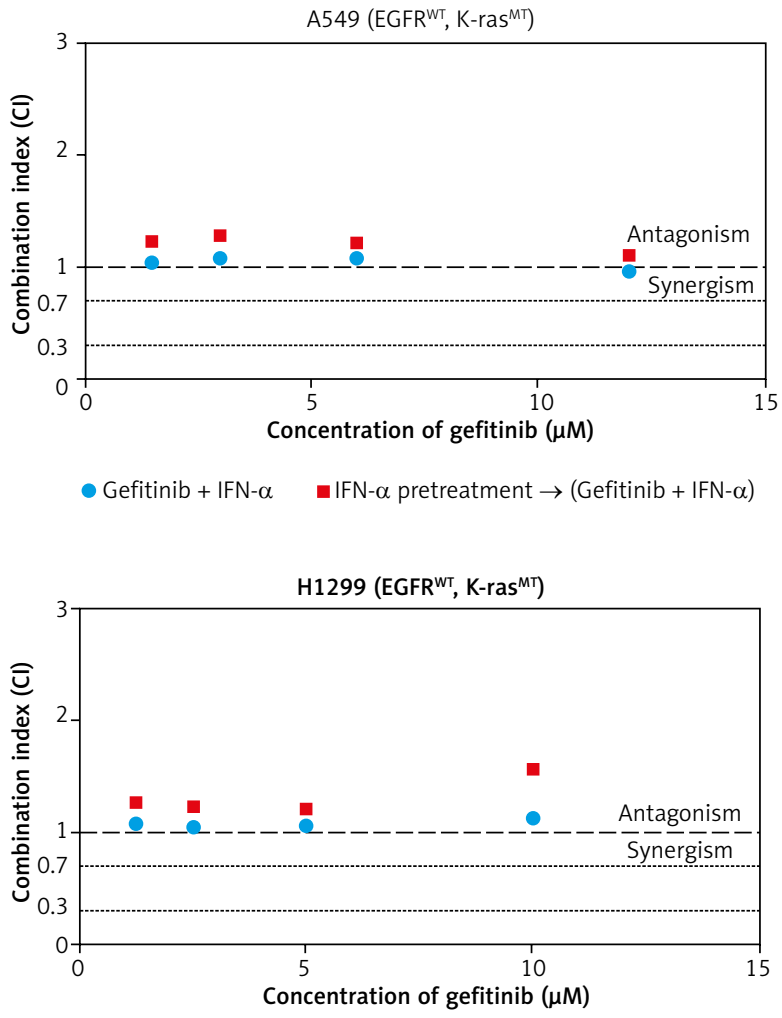

- Gefitinib + IFN- $\alpha \quad$ IFN- $\alpha$ pretreatment $\rightarrow($ Gefitinib + IFN- $\alpha)$

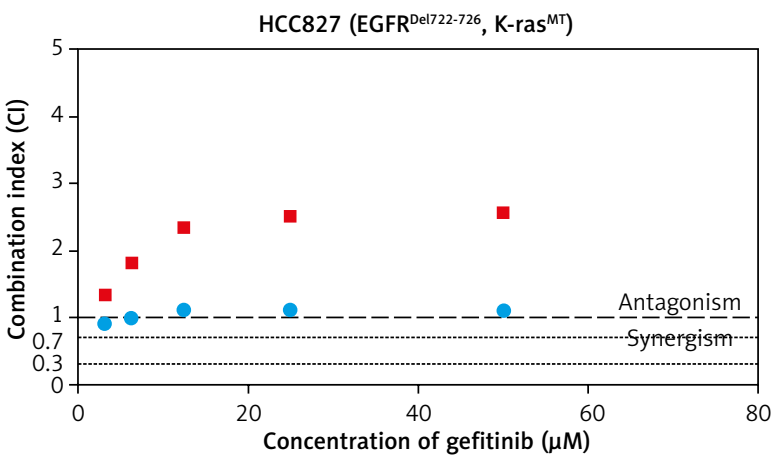

- Gefitinib + IFN- $\alpha \quad$ IFN- $\alpha$ pretreatment $\rightarrow($ Gefitinib + IFN- $\alpha)$

Fig. 2. Additive/antagonistic antiproliferative effect of IFN- $\alpha$ /gefitinib combination on human NSCLC cell lines. A) Cell survival was determined by MTT assay. B) The Cls defining the growth inhibitory effects of the combination treatment of gefitinib and IFN- $\alpha$. Combinations were antagonistic when $\mathrm{Cls}>1.0$, and additive when $\mathrm{Cl} s=0.9-1.0$. Points, mean of three individual treatments. MT, mutation type 
tered with IFN- $\alpha$, it resulted in an additive interaction in all four cell lines, as shown by the $\mathrm{Cl}$ values $(\mathrm{Cl}=1$; Fig. 2$)$. The mean $\mathrm{Cl}$ values of gefitinib + IFN- $\alpha$ for each cell line are listed in Table 1 (Gefitinib + IFN- $\alpha$ ); all of the $\mathrm{Cl}$ values were approximately 1.

Nevertheless, when the cells were pretreated with

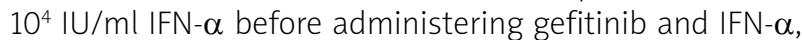
there were antagonistic interactions between gefitinib and IFN- $\alpha$ in three cell lines. IFN- $\alpha$ pretreatment induced an antagonistic effect between gefitinib and IFN- $\alpha$ (Fig. 2), as demonstrated by the higher mean $\mathrm{Cl}$ values of the gefitinib + IFN- $\alpha$ combination after IFN- $\alpha$ pretreatment (Table 1 , $\mathrm{Cls}_{\text {gefitinib+1FN- } \alpha}$ VS. Cls IFN- $\alpha \rightarrow$ gefitinib+FN- $\left.\alpha, p<0.005\right)$. In these cell lines, the cell survival rate according to each concentration of gefitinib increased after the IFN- $\alpha$ pretreatment (Table 1, Fig. 2).

\section{IFN- $\alpha$ can reduce gefitinib antiproliferation}

To gain insight into whether IFN- $\alpha$ could influence gefitinib sensitivity, cell survival was evaluated after gefitinib treatment following IFN- $\alpha$ pretreatment. After the pretreatment, cell survival rates were significantly increased in the A549 and H1299 cell lines as the gefitinib concentration increased; a significant reduction was observed at each gefitinib concentration in the HCC827 cell line (Fig. 3A, cell survival rate ${ }_{\text {IFN- } \alpha \rightarrow \text { gefitinib }}$ VS. cell survival rate ${ }_{\text {placebo } \rightarrow \text { gefitinib }}$ $p<0.05)$.

To determine whether IFN- $\alpha$ could inhibit gefitinib-induced apoptosis, the outcome of the Annexin V/PI detection demonstrated that there was a decrease in gefitinib-induced apoptosis after the IFN- $\alpha$ pretreatment (Fig. 3B, $p<0.05$ ).

\section{IFN- $\alpha$ and gefitinib inhibit STAT3 activation}

Previously, many studies reported that IFN- $\alpha$ could activate EGFR signalling by upregulating EGFR expression $[7,8]$. We investigated whether IFN- $\alpha$ could induce EGFR signalling activation in NSCLC cells. Two cell lines were examined: $\mathrm{H} 1299$ and HCC827, where IFN- $\alpha$ pretreatment inhibited the effect of gefitinib significantly. IFN- $\alpha$ could not activate EGFR phosphorylation but could inhibit STAT3 phosphorylation in both cell lines (Fig. 4). Gefitinib inhibited EGFR activation in both cell lines and inhibited STAT3 activation in both cell lines (Fig. 4B).

\section{Discussion}

The present findings are not consistent with those of previous studies, which showed that IFN- $\alpha$ could enhance the antiproliferation of EGFR-TKI in colon cancer cells [5], renal cell carcinoma [2], and hepatocellular carcinoma [3]. In our study, IFN- $\alpha$ reduced the gefitinib sensitivity of NSCLC cells that contained EGFR-TKI-sensitive mutations.

We also noted that IFN- $\alpha$ alone had a mild antiproliferative effect on the NSCLC cell lines: the rate of cell survivalinhibition was less than $50 \%$ even at $10^{5} \mathrm{IU} / \mathrm{mL}$ IFN- $\alpha$ (Fig. 1), and the rate of IFN- $\alpha$-induced apoptosis was very low (Fig. 3B). As expected, the three cell lines, carrying different EGFR and K-Ras gene types, responded differently to gefitinib alone: A549 and H1299 cells were less susceptible to gefi-
Table 1. Combination indexes for gefitinib and IFN-/combination

\begin{tabular}{lccc} 
Cell line & \multicolumn{3}{c}{ Combination Indexes } \\
\cline { 2 - 4 } & Gefitinib + IFN- $\alpha$ & $\begin{array}{c}\text { Gefitinib + IFN- } \alpha \\
\text { after IFN- } \alpha\end{array}$ & pretreatment \\
A549 & $1.040 \pm 0.031$ & $1.205 \pm 0.032^{*}$ & $p=0.002$ \\
H1299 & $1.080 \pm 0.043$ & $1.332 \pm 0.058^{*}$ & $p=0.002$ \\
Hcc827 & $1.078 \pm 0.063$ & $1.828 \pm 0.173^{*}$ & $p=0.001$
\end{tabular}

Each value represents the mean $\pm S E$ of all combination index (Cls) values for each cell line. The $p$-values were analysed by a two-tailed Student's t-test. ${ }^{*} p<0.05$, statistically significant; NS, $p>0.05$, statistically not significant.

Cl value: $<0.9$ - synergism, 0.9-1.0 - additivity, > 1-antagonism.

tinib while the HCC827 cell line was sensitive to its effects (Fig. 2).

Disappointingly, there was no interaction between gefitinib and IFN- $\alpha$ when they were administered in combination in these cell lines. The Cls values demonstrated that the gefitinib + IFN- $\alpha$ combination effects were additive (Table 1, Fig. 2). Surprisingly, however, the effect was reduced after IFN- $\alpha$ pretreatment. Notably, the antiproliferation of gefitinib alone was reduced after IFN- $\alpha$ pretreatment in the three cell lines (Fig. 3). The inhibition to gefitinib was the most significant in the HCC827 cell line.

Previous studies have suggested that IFN- $\alpha$ can upregulate EGFR expression in cancer cells [14, 15], and others have postulated that the increases in EGFR expression tend to be accompanied by enhanced activity of EGFR signalling. Nevertheless, based on our observations, EGFR activation was not associated with IFN- $\alpha$ in the H1299 or HCC827 cells (Fig. 4).

STAT3 is a STAT family member that is involved in oncogenesis and tumour progression [16]; previous studies have shown that STAT3 is activated in lung cancer, and its activation may stem from EGFR mutations [17]. Similarly, it was found that STAT3 was activated in the two cell lines (Fig. 4). However, IFN- $\alpha$ can activate the Janus kinase 1 (JAK1)/STAT pathway [18] and inhibit STAT3 phosphorylation [19]; our research also showed that IFN- $\alpha$ inhibited p-STAT3 in the NSCLC cell lines. It is worth mentioning that prior studies have shown that there is cross-talk between JAK/STAT and EGFR signalling in the regulation of hyperproliferation [20], and that EGFR is an upstream activator of STAT3 that can mediate EGFR signalling [16, 17, 21]; therefore, EGFR-TKIs may be able to inhibit STAT3 activation.

Interestingly, Figure 4 shows that gefitinib could inhibit p-STAT3 expression in the H1299 and HCC827 cells in which IFN- $\alpha$ could inhibit gefitinib-induced apoptosis to some extent. Therefore, we hypothesised that EGFR signalling may be dependent on STAT3 activation, in other words, the inhibitory effect of gefitinib may depend on STAT3 activation, and this point of view has been reported [17]. The phosphorylation of STAT3 was inhibited by IFN- $\alpha$ pretreatment; therefore, the EGFR pathway, being somewhat dependent on STAT3 activation, may not have been activated, thereby reducing the gefitinib sensitivity of these cell lines.

Although IFN- $\alpha$ may increase the susceptibility of EGFR-TKI in other tumour cells, but in lung cancer there is 
A

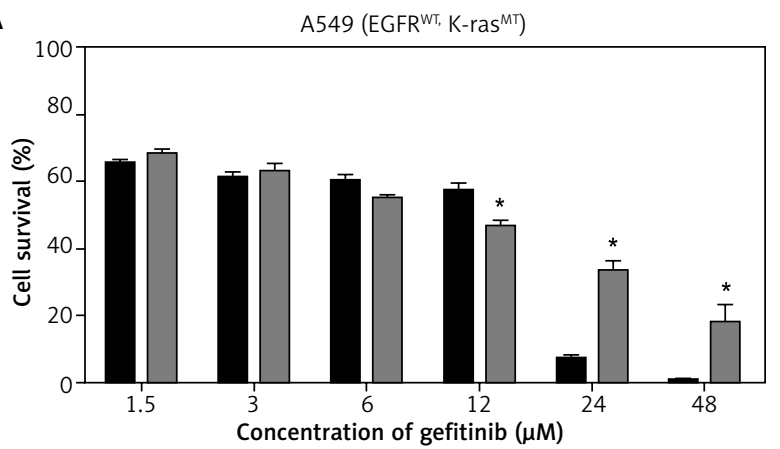

H1299 (EGFR ${ }^{\mathrm{WT}}$, K-ras ${ }^{\mathrm{MT}}$ )

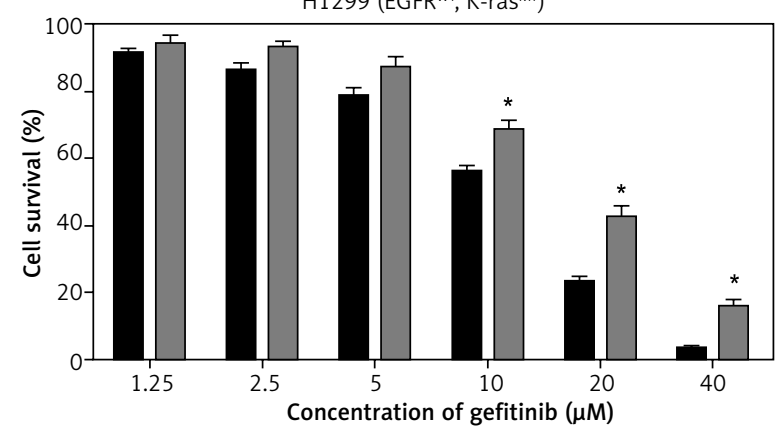

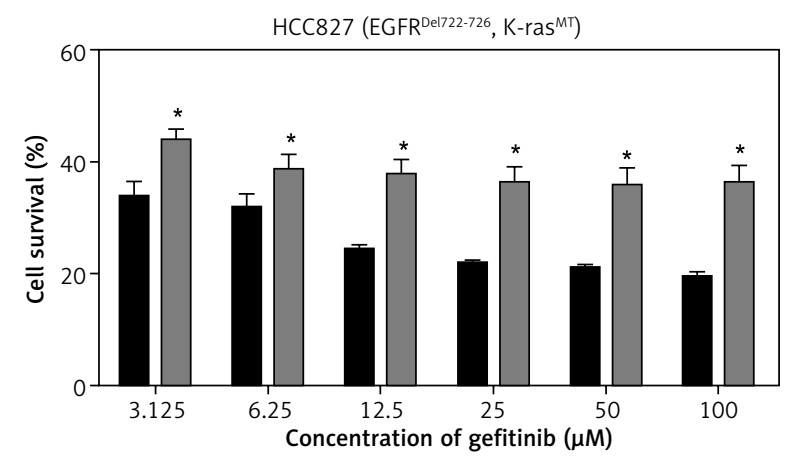

placebo $\rightarrow$ gefitinib

$\square 10^{4} \mathrm{IU} / \mathrm{ml}$ IFN- $\alpha \rightarrow$ gefitinib

B
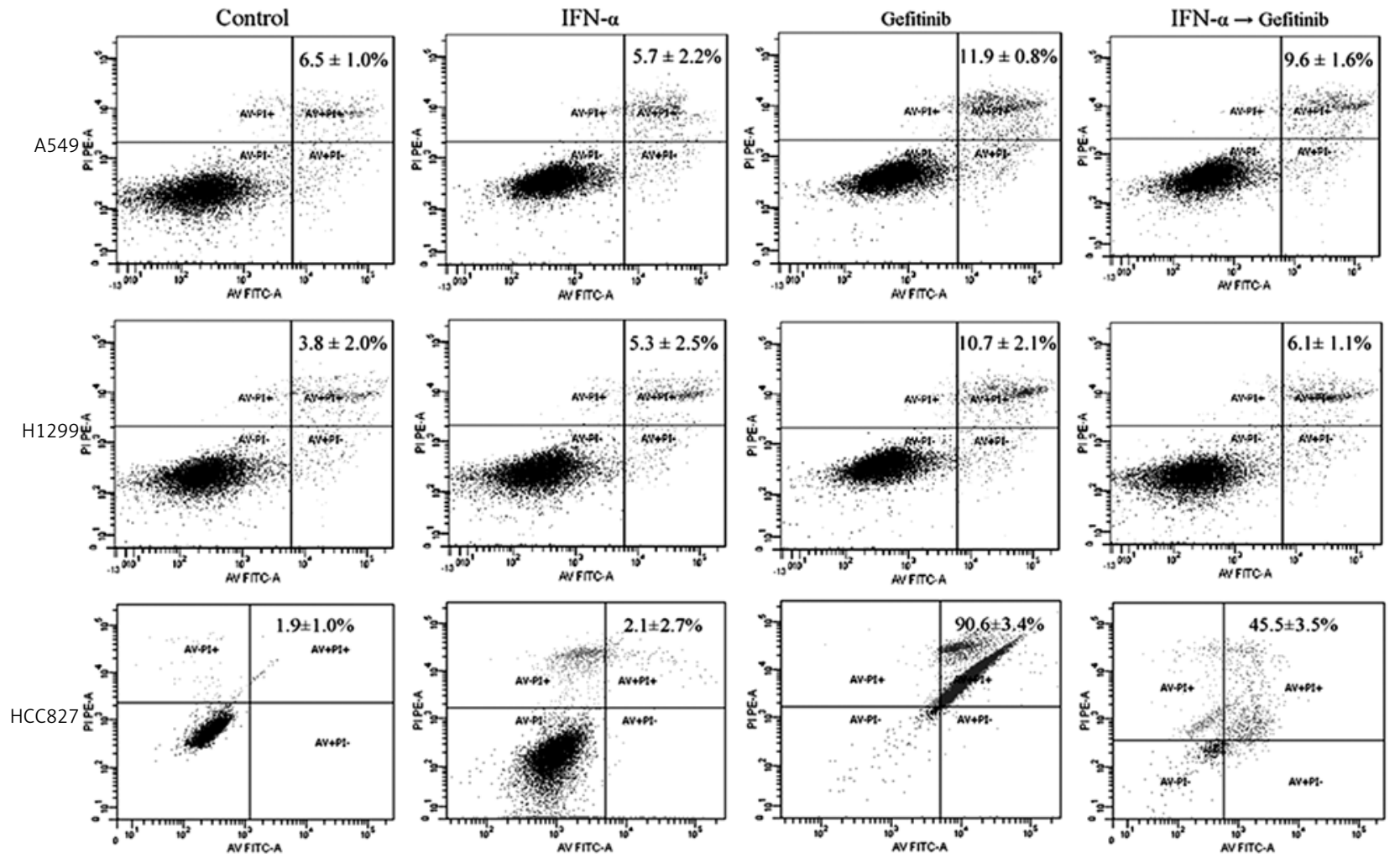

Fig. 3. IFN- $\alpha$ decreased antiproliferation of gefitinib. A) The antagonistic effect of IFN- $\alpha$ pretreatment on the antiproliferative effect of gefitinib on human NSCLC cell lines was evaluated by MTT assay. B) Apoptosis in the cell lines was analysed by flow cytometry for Annexin V/ $\mathrm{PI}$ staining. The results (top and bottom right panels) are expressed as the percentage of the apoptotic cells. Data are reported as the mean \pm SE of three determinations, $p<0.05$ for gefitinib vs. IFN- $\alpha \rightarrow$ gefitinib 

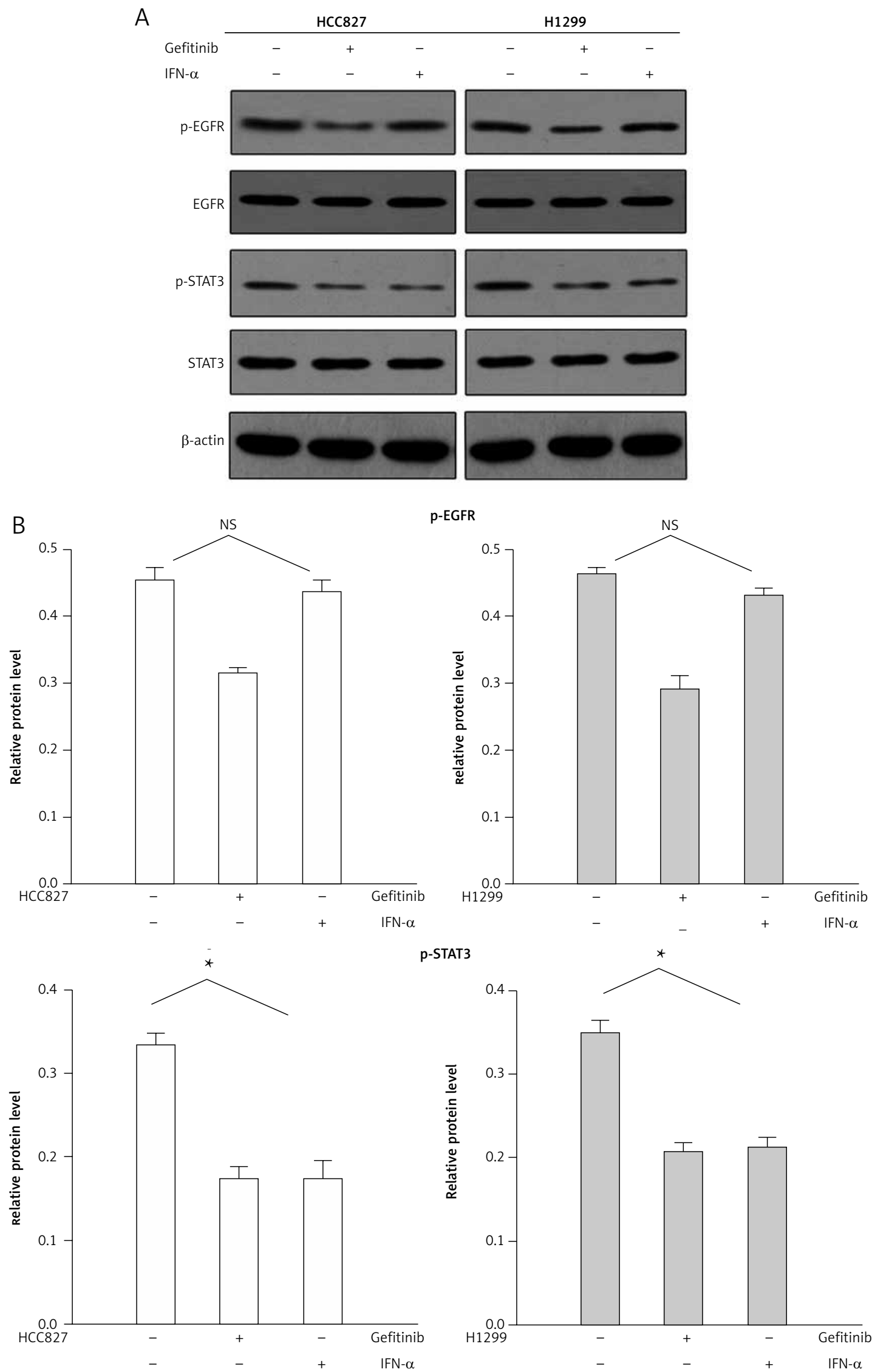

Fig. 4. IFN- $\alpha$ and gefitinib inhibit STAT3 activation. A) p-EGFR/EGFR and p-STAT3/STAT3 were analysed by western blot. The whole protein from $\mathrm{H} 1299$ and $\mathrm{HCC} 827$ cells treated for 48 hours with IFN- $\alpha\left(10^{4} \mathrm{IU} / \mathrm{ml}\right)$ and gefitinib $(10 \mathrm{nM})$ alone with IFN- $\alpha$ was extracted. B) The expression levels were analysed by the ratio of optical density with $\beta$-actin. STAT3 activation was inhibited by IFN- $\alpha$ and gefitinib in both cell lines, $p<0.05$ 
no similar action. In contrast, the antiproliferation of EGFR-TKI can be inhibited by IFN- $\alpha$ in lung cancer. Our data suggests that EGFR-TKI should avoid sequential application with IFN- $\alpha$. In addition, as we know, finding the mechanisms of EGFR-TKI resistance is the current focus, IFN- $\alpha$ inactivates gefitinib in NSCLC, it may provide a new idea to explore and enrich the mechanisms of EGFR-TKI resistance. We hypothesised that the potential cause may be that IFN- $\alpha$ inhibits phosphorylation of STAT3, which might be dependent on EGFR signal activation. However, this hypothesis must be verified with further research.

The authors express their gratitude to the Wu Jieping Foundation (No. 320.6750.12241), Natural Science Foundation of China (No. 81102012), Natural Science Foundation of China (No. 91229104), and Zhejiang medicine scientific research fund projects (No. 2010ZB073).

The authors declare no conflict of interest.

\section{References}

1. Baselga J, Averbuch SD. ZD1839 ('Iressa') as an anticancer agent. Drugs 2000; 60 Suppl 1: 33-40; discussion 41-32.

2. Amato RJ, Jac J, Hernandez-McClain J. Interferon-alpha in combination with either imatinib (Gleevec) or gefitinib (Iressa) in metastatic renal cell carcinoma: a phase II trial. Anticancer Drugs 2008; 19: 527-33.

3. Huether A, Hopfner M, Sutter AP, Schuppan D, Scherübl H. Erlotinib induces cell cycle arrest and apoptosis in hepatocellular cancer cells and enhances chemosensitivity towards cytostatics. J Hepatol 2005; 43: 661-9.

4. Yang JL, Qu XJ, Hayes VM, Brenner PC, Russell PJ, Goldstein D. Erlotinib (OSI-774)-induced inhibition of transitional cell carcinoma of bladder cell line growth is enhanced by interferon-alpha. BJU Int 2007; 99: 1539-45.

5. Yang L, Wang F, He F, Huang L. The effect of combining interferon-alpha and gefitinib in human colon cancer cell lines. West Indian Med J 2011; 60: 107-13.

6. Yang JL, Qu XJ, Russell PJ, Goldstein D. Interferon-alpha promotes the anti-proliferative effect of gefitinib (ZD 1839) on human colon cancer cell lines. Oncology 2005; 69: 224-38.

7. Bruzzese F, Di Gennaro E, Avallone A, Pepe S, Arra C, Caraglia M, Tagliaferri P, Budillon A. Synergistic antitumor activity of epidermal growth factor receptor tyrosine kinase inhibitor gefitinib and IFN-alpha in head and neck cancer cells in vitro and in vivo. Clin Cancer Res 2006; 12: 617-25.

8. Diaz A, Batista AE, Montero E. Interferon-alpha conditioned sensitivity to an anti-epidermal growth factor receptor monoclonal antibody in a human lung cancer cell line with intermediate expression of the receptor. J Interferon Cytokine Res 2009; 29: 433-40.

9. Goldstein D, Bushmeyer SM, Witt PL, Jordan VC, Borden EC. Effects of type I and II interferons on cultured human breast cells: interaction with estrogen receptors and with tamoxifen. Cancer Res 1989; 49: 2698-702.

10. Mok TS, Wu YL, Thongprasert S, et al. Gefitinib or carboplatin-paclitaxel in pulmonary adenocarcinoma. N Engl J Med 2009; 361: 947-57.

11. Fukuoka M, Wu YL, Thongprasert S, et al. Biomarker analyses and final overall survival results from a phase III, randomized, open-label, first-line study of gefitinib versus carboplatin/paclitaxel in clinically selected patients with advanced non-small-cell lung cancer in Asia (IPASS). J Clin Oncol 2011; 29: 2866-74.

12. Mitsudomi T, Morita S, Yatabe Y, et al. Gefitinib versus cisplatin plus docetaxel in patients with non-small-cell lung cancer harbouring mutations of the epidermal growth factor receptor (WJ-
TOG3405): an open label, randomised phase 3 trial. Lancet Oncol 2010; 11: 121-8.

13. Pao W, Miller V, Zakowski M, et al. EGF receptor gene mutations are common in lung cancers from "never smokers" and are associated with sensitivity of tumors to gefitinib and erlotinib. Proc Natl Acad Sci U S A 2004; 101: 13306-311.

14. Yang JL, Qu XJ, Russell PJ, Goldstein D. Interferon-alpha promotes the anti-proliferative effect of Erlotinib (OSI-774) on human colon cancer cell lines. Cancer Lett 2005; 225: 61-74.

15. Ou XJ, Yang J, Russell PJ, Goldstein D. Changes in epidermal growth factor receptor expression in human bladder cancer cell lines following interferon-alpha treatment. J Urol 2004; 172: 733-8.

16. Quesnelle KM, Boehm AL, Grandis JR. STAT-mediated EGFR signaling in cancer. J Cell Biochem 2007; 102: 311-9.

17. Haura EB, Zheng Z, Song L, Cantor A, Bepler G. Activated epiderma growth factor receptor-Stat-3 signaling promotes tumor survival in vivo in non-small cell lung cancer. Clin Cancer Res 2005; 11: 8288-94.

18. Jonasch E, Haluska FG. Interferon in oncological practice: review of interferon biology, clinical applications, and toxicities. Oncologist 2001; 6: 34-55.

19. Thyrell L, Arulampalam V, Hjortsberg L, Farnebo M, Grandér D, Pokrovskaja Tamm K. Interferon alpha induces cell death through interference with interleukin 6 signaling and inhibition of STAT3 activity. Exp Cell Res 2007; 313: 4015-24.

20. Cordero JB, Stefanatos RK, Myant K, Vidal M, Sansom OJ. Non-autonomous crosstalk between the Jak/Stat and Egfr pathways mediates Apc1-driven intestinal stem cell hyperplasia in the Drosophila adult midgut. Development 2012; 139: 4524-35.

21. Hambek M, Baghi M, Strebhardt K, May A, Adunka O, Gstöttner W, Knecht R. STAT 3 activation in head and neck squamous cell carcinomas is controlled by the EGFR. Anticancer Res 2004; 24: 3881-6.

\section{Address for correspondence}

\section{Jianjin Huang}

Cancer Institute

School of Medicine

Zhejiang University

88 Jiefang Road

310009 HangZhou, China

e-mail: hhjj@medmail.com.cn

Submitted: 18.01.2014

Accepted: 24.04 .2015 